\title{
Going through the lockdown: a longitudinal study on the psychological consequences of the coronavirus pandemic
}

\author{
Salvatore Gullo, ${ }^{1}$ Ilaria Misici, ${ }^{1}$ Arianna Teti, ${ }^{1}$ Michele Liuzzi, ${ }^{2}$ Enrico Chiara ${ }^{2}$ \\ ${ }^{1}$ Dipartimento di Scienze Psicologiche, Pedagogiche, dell'Esercizio Fisico e della Formazione (DSPPEFF), Università degli Studi di \\ Palermo; ${ }^{2}$ Dipartimento di Psicologia, Università degli Studi di Torino, Italy
}

\begin{abstract}
Coronavirus 2019 pandemic lockdown in Italy lasted for 2 months, 1 week and 2 days. During this long period, one of the longest in Europe, the restrictions produced effects on people's psychological well-being, with consequences that also continued after lockdown. The purpose of the study is to investigate these effects and how they changed in the general population over a period of time. We are also interested in exploring people's post-lockdown anxiety and concerns. We conducted an online survey using snowball sampling techniques. The longitudinal study consisted of four administrations covering a period of 10 weeks between April (baseline) and June (last follow-up). Levels of anxiety and depression were assessed by GAD-7 and PHQ-9, coping strategies were assessed by Brief Resilient Coping Scale (BRCS) and social support was assessed by MSPSS. Post-lockdown anxiety was explored by developing a set of ad-hoc questions. PCA was used to determine the principal categories of post-lockdown anxiety/concern resulting from the ad-hoc questions. Longitudinal data, given their nested structure, were analyzed through mixed modeling. Of the 411 responders at baseline, 169 had at least 3 out of 4 data points; the analysis was therefore conducted on this sample. Levels of depression and anxiety were found to be significantly higher in the study sample in comparison with normative samples for each of the fourtime points; levels of coping showed that scores from the study sample were significantly lower than normative data at all-time points. Levels of perceived social support were significantly lower than normative data at the baseline and the first follow-up. The results of the study suggest that the lockdown experience had enduring consequences on the mental health of individuals. Prevention and support interventions to limit the psychological distress caused by COVID-19 should be taken into consideration in countries experiencing a second wave of the pandemic.
\end{abstract}

Key words: Coronavirus; social support during COVID-19; anxiety COVID-19 related; depression COVID-19 related; COVID-19 longitudinal study; negative emotions COVID-19 related.

Correspondence: Salvatore Gullo, Dipartimento di Scienze Psicologiche, Pedagogiche, dell'Esercizio Fisico e della Formazione (DSPPEFF), Università degli Studi di Palermo, Viale delle Scienze, Edificio 15, 90128 Palermo, Italy.

E-mail: salvo.9g@gmail.com

See online appendix for Supplementary Tables.

Citation: Gullo, S., Misici, I., Teti, A., Liuzzi, M., \& Chiara, E. (2020). Going through the lockdown: a longitudinal study on the psychological consequences of the coronavirus pandemic. Research in Psychotherapy: Psychopathology, Process and Outcome, 23(3), 211-221. doi: 10.4081/ripppo.2020.494

Received for publication: 7 September 2020.

Revision received: 26 November 2020.

Accepted for publication: 27 November 2020.

This work is licensed under a Creative Commons Attribution NonCommercial 4.0 License (CC BY-NC 4.0).

${ }^{\circ}$ Copyright: the Author(s), 2020

Licensee PAGEPress, Italy

Research in Psychotherapy:

Psychopathology, Process and Outcome 2020; 23:211-221

doi:10.4081/ripppo.2020.494

\section{Introduction}

\section{Restrictive measures used in Italy}

The coronavirus 2019 (COVID-19) pandemic originated in Wuhan (China) and spread rapidly around the world from December 2019; in Italy, due to the increase in COVID-19 cases, in March 2020, the government ordered a period of precautionary lockdown, with restrictions on non-essential movement and business. This lockdown period was divided into two periods, named Phase 1 and Phase 2.

In detail, except for people testing positive for COVID-19, who were not allowed to leave their homes under any circumstances during Phase 1, the government demanded the closure of commercial activities, with the exception of those considered essential (e.g. supermarkets and pharmacies). There was also an imposed obligation to stay at home and avoid any social interaction with others, except cohabitants; movement was only allowed in three cases: for work reasons (e.g. health workers), for issues of proven necessity (e.g. grocery shopping) and for health reasons. In the last case, those who showed flu symptoms and/or fever, had the obligation to report their condition to the health services by telephone, and were 
not allowed to go to the doctor or to a hospital. Any movement had to be justified through self-certification, to be carried and to be shown if requested by the police to check the veracity of the declaration.

During Phase 2, the measures became less restrictive, allowing the reopening of many businesses and the possibility to meet up with relatives in a first instance and, subsequently, also with close friends. The obligation to wear protective wear was still required, especially in public areas, as well as the maintaining of a social distance (1 meter) between people.

The consequence was that during this period people were forced to stay at home, an imposition that had severe consequences on people's physical health and psychological well-being (Kumar \& Nayar, 2020).

\section{Psychological consequences of pandemic}

The results in literature, referring to previous epidemics, suggest that people who had been quarantined, reported a high prevalence of symptoms of psychological distress and disorders, such as depression, low mood, irritability, insomnia, post-traumatic stress symptoms and anger. In addition, after quarantine, many continued to engage in avoidant behavior (Brooks et al., 2020). Previous episodes of acute severe respiratory syndrome (SARS) have shown substantial and long-lasting effects, well beyond the initial biological risk. Follow-up studies at short-term (1 month), mediumterm (1 year) and long-term (4 years), on patients, their family members, caregivers and health professionals, have documented the presence and persistence, over time, of significant levels of anxiety, depression, panic attacks, psychomotor arousal and post-traumatic stress symptoms (Hawryluck et al., 2004; Wu et al., 2009).

Numerous studies were conducted during this period of quarantine to investigate its psychological consequences on people, first in China and then in the rest of the world. In general, results confirmed that lockdown and post-lockdown resulted in psychological pressure that might be expressed in terms of higher anxiety or lower mood (Ozamiz-Etxebarria, Dosil-Santamaria, PicazaGorrochategui, \& Idoiaga-Mondragon, 2020; Wang et al., 2020a; Wang et al., 2020b). A survey conducted in China, on over 52,000 individuals, showed that 5\% reported severe psychological disorders and 35\% reported psychological distress (Qiu et al., 2020). The review of literature conducted by Serafini et al. (2020) showed that the most relevant psychological reactions to COVID-19 infection are: uncontrolled fears related to infection, pervasive anxiety, frustration and boredom, disabling loneliness. Another study showed that individuals during the first period of the COVID-19 pandemic reported elevated levels of depression (43.4\%), anxiety (45.4\%) and PTSD symptoms (31.8\%) (Liu, Zhang, Wong, Hyun, \& Hahm, 2020).

Higher levels of anxiety and depression during the COVID-19 lockdown seem to be linked to the female gender, young age and low annual income (Smith et al.,
2020). A longitudinal study conducted in China during the initial outbreak, and during the four weeks after the epidemic's peak, suggests levels of relative long-term stability in stress, anxiety and depression levels; it reports an absence of significant differences in these three domains and a statistically, but not clinically, significant temporal reduction in PTDS symptoms (Wang et al., 2020b).

\section{Protective factors}

Several studies have found that protective factors, such as coping and social support, have a positive influence, reducing (during quarantine) negative effects due to previous health emergencies. During the SARS virus epidemic, some people reported finding comfort through distractions, thus avoiding thinking about the situation. This highlighted the importance of social support; in fact, many caregivers were relieved to be taking care of their family members (Chiang, Chen, \& Sue, 2007).

With regard to the COVID-19 lockdown, literature suggests that resilience, coping and social support can mitigate the impact of quarantine on one's psychological well-being (Serafini et al., 2020). The study by Liu et al. (2020) reports that high levels of resilience were linked with low levels of anxiety; additionally, high levels of perceived family support were linked with low depression and PTSD symptoms, although levels of perceived friend support were not linked with any psychological outcomes. Coping behavior can combat and alleviate stress and anxiety problems caused by COVID-19 (Fullana, Hidalgo-Mazzei, Vieta, \& Radua, 2020). Among the coping strategies, those regarding care for one's personal daily life, such as time dedicated to hobbies or outdoors activities, were very effective. This simple behavior has proven to be predictive of lower levels of depression. It is also important to note how positive coping strategies can reduce stress; instead, negative coping strategies, such as guilt and avoidance, might increase levels of stress (Vinothkumar et al., 2016). Positive coping, generally associated with a good quality of life and personal satisfaction, can alleviate some psychological symptoms (Chew, Wei, Vasoo, Chua, \& Sim, 2020) and is significantly and negatively correlated with anxiety. Certainly, one of the most effective coping strategies is the desire for family support (Wang, Wang, \& Yang, 2020).

In a study carried out on the Egyptian adult population (510 subjects) it was found that although $24.2 \%$ of people experienced an increase in support from friends, they sought more support from family members $(40.6 \%)$. $46.5 \%$ shared their feelings with family members more often during the quarantine period; in fact 330 people reported an increase in family care $(64.7 \%)$ (El-Zoghby, Soltan, \& Salama, 2020).

\section{Study aims}

The present study has three main aims. First of all, we were interested in grasping the affective status of the sam- 
ple recruited, by measuring levels of anxiety and depressive feelings during the period characterized by the rapid spread of the contagion and the recent imposition of restrictive measures (lockdown) by the Italian government. At the same time, we wanted to test the effect of protective factors, such as coping resources and support from family and friends. Specifically, we hypothesized that, at baseline, these protective factors might have an effect on reducing people's levels of anxiety and depression.

Regarding the course of the pandemic, and the consequent accumulation of psychological distress due to the prolongation of the emergency and the maintenance of lockdown, the second aim was to study the longitudinal trend of the levels of anxiety and depression and verify the effects of protective factors in a mid-term period (3 months). As regards this aim, we hypothesized that these effects would endure and be confirmed during and after lockdown.

Lastly, we were particularly interested in focusing on the transition between lockdown and post-lockdown. Considering the absolute novelty that the COVID-19 pandemic represents and the tremendous consequences that it has generated, we aimed to explore the kind of concerns and reactions that arose when people were allowed to return to their everyday existence. Given its exploratory nature, no hypothesis was set for this aim.

\section{Method}

\section{Sampling procedure}

The study was conducted with an online questionnaire, to which Italian adults were invited to participate through social networks (e.g., Facebook, Instagram) and WhatsApp. To recruit the initial sample, snowball sampling techniques were used; 40 initial units were selected, to whom the link was sent in order to participate in the online survey (T1 questionnaire) together with a request to indicate a further 10 units belonging to the same population. The same questionnaire link was then also sent to these subjects. The recruitment window for $\mathrm{T} 1$ was open from April, 2, 2020 to April, 9, 2020; the second administration (T2) was open from April, 20, 2020 to April, 29, 2020. The first two administrations were both carried out during Phase 1 (total ban on not strictly necessary relocations) of the outbreak period, imposed by the Italian government to confine the health emergency. Similarly, the third administration (T3) was sent immediately after the sample survey from May, 4, 2020 to May, 11, 2020 and the last administration (T4) from May, 28, 2020 to June, 4, 2020. These administrations were carried out at the beginning and the end of Phase 2 (gradual recovery of activities and social life), respectively. The four time points were selected to analyze the trend of the psychological impact caused by the outbreak and the COVID-19 pandemic. In order to participate in the online survey, sub- jects had to sign their informed consent, and, regarding the aims of the study, agree to the confidentiality of the data, the possibility of withdrawing from the study at any moment and the fact that the data are protected by UE GDPR 679/2016 and Italian law 196/2003. The informed consent also indicated the possibility of receiving raw data at the end of the study. Participants were also informed of the longitudinal design of the study and, for this reason, they had to create an anonymous code as regards the possibility of matching their data at subsequent time-points of the survey; those who accepted were also asked to complete other administrations, to indicate a personal contact (i.e., e-mail address or phone number) in order to receive subsequent links to the questionnaires. The study was approved by the Ethic Committee of the University of Palermo, 'UNIPA-151 - Prot. 521-04/05/2020'.

\section{Statistical strategy}

Comparisons between groups were conducted through t-test, ANOVA, and nonparametric tests whenever necessary. Associations between continuous variables were tested by Pearson's $r$ or linear regression. The Hierarchical Linear Model was used to test longitudinal data. The model includes two levels; level 1 was a within-subject level accounting for variance due to the repeated measuring of each participant, and level 2 a between-subjects level accounting for variance due to differences among subjects. Analyses were conducted separately for GAD-7 and PHQ-9 as dependent variable (DV). Time was centred to the first administration $(\mathrm{T} 1=0)$ to facilitate the interpretation of the results. In the first model time effects were tested by introduction of linear and quadratic terms:

Level-1 Model

$D V_{\mathrm{ti}}=\pi_{0 \mathrm{i}}+\pi_{\mathrm{li}} *\left(t i m e_{\mathrm{ti}}\right)+\pi_{2 \mathrm{i}} *\left(t i m e_{\mathrm{ti}}^{2}\right)+e_{\mathrm{ti}}$

Level-2 Model

$\pi_{0 \mathrm{i}}=\beta_{00}+r_{0 \mathrm{i}}$

$\pi_{1 \mathrm{i}}=\beta_{10}+r_{1 \mathrm{i}}$

$\pi_{2 \mathrm{i}}=\beta_{20}+r_{2 \mathrm{i}}$

In the second model predictors (BRCS and MSPSS) were added as independent variables (IV) in the level-1 and level-2 equations:

Level-1 Model

$D V_{\mathrm{ti}}=\pi_{0 \mathrm{i}}+\pi_{1 \mathrm{i}}^{*}\left(t i m e_{\mathrm{ti}}\right)+\pi_{2 \mathrm{i}}^{*}\left(\operatorname{time}_{\mathrm{ti}}^{2}\right)+\pi 3 \mathrm{i}^{*}\left(I V_{\mathrm{ti}}\right)+e_{\mathrm{ti}}$

Level-2 Model

$\pi_{0 \mathrm{i}}=\beta_{00}+r_{0 \mathrm{i}}$

$\pi_{1 \mathrm{i}}=\beta_{10}+\beta_{11} *\left(I V_{\mathrm{i}}\right)+r_{1 \mathrm{i}}$

$\pi_{2 \mathrm{i}}=\beta_{20}+\beta_{21} *\left(I V_{\mathrm{i}}\right)+r_{2 \mathrm{i}}$

$\pi_{3 \mathrm{i}}=\beta_{30}+r_{3 \mathrm{i}}$

Data collected through the 13 ad-hoc questions, relating to the transition between outbreak and post-outbreak, 
were summarized by a principal component analysis (PCA) with Promax oblique rotation. Eigenvalues greater than 1 were considered in order to determine the number of components. Items with loadings below 0.40 or crossloadings of 0.40 or higher on two or more factors were removed (Howard, 2016).

\section{Measures}

An online survey was used in order to collect demographic data (i.e., age, gender, education and occupation), anxiety and depression levels, coping strategies, levels of perceived social support and worries about the post-outbreak phase.

The General Anxiety Disorder-7 (GAD-7; Spitzer, Kroenke, Williams \& Löwe, 2006), is a 7-items self-report questionnaire investigating worry and anxiety symptoms. Responses were rated on a 4-point Likert scale $(0=$ "not at all", $3=$ "nearly every day"). The total score is calculated by the sum of single items; scores equal to, or higher than 10, were considered a case of probable generalized anxiety. The questionnaire showed good reliability and construct validity (Kroenke, Spitzer, Williams, Monahan \& Löwe, 2007; Lowe et al., 2008). In our sample, Cronbach Alpha was 0.848 .

The Patient Health Questionnaire-9 (PHQ-9; Spitzer, 1999), is a 9-item self-report questionnaire concerning depressive symptoms. Each item is scored on a 4-point Likert scale ( $0=$ "not at all", $3=$ "nearly every day"). The total score is calculated by the sum of single items; scores greater than 10 were considered to be a case of probable depression. The questionnaire showed good psychometric properties (Kroenke, Spitzer \& Williams, 2001). In our sample Cronbach Alpha was 0.841.

The Multidimensional Scale of Perceived Social Support (MSPSS; Zimet, Dahlem, Zimet \& Farley, 1988), is a 12 -item inventory measuring the levels of perceived social support. The inventory is composed of three subscales: "family", "friends" and "significant other". We included, in the online survey, only the 8 items relative to the "family" and "friends" subscales. Each item is scored on a 7-point Likert scale (1= "very strongly disagree", 7= "very strongly agree"). The total score is calculated by taking the mean of single items; a higher score corresponds to higher levels of perceived social support. The inventory showed good psychometric properties, with good internal reliability for subscales (Zimet et al., 1988). In our sample Cronbach Alpha was 0.931 on the "family" subscale, and 0.956 on the "friends" subscale.

The Brief Resilient Coping Scale (BRCS; Sinclaire \& Wallston, 2004), is a 4-item self-report questionnaire investigating the ability to cope with stress in a highly adaptive manner. Each item is scored on the 5-point Likert scale ( $1=$ "does not describe me at all", $5=$ "describes me very well"). The total score is calculated by the sum of single items; a higher score corresponds to higher ability to cope with stress. The BRCS has adequate in- ternal consistency and test-retest reliability (Sinclaire \& Wallston, 2004). In our sample Cronbach Alpha was 0.649 .

After the third administration, a set of 13 ad-hoc questions was introduced to explore post-lockdown anxiety and fear. An initial list of items was developed independently by two researchers (A.T. and I.M) based on the literature related to PTSD (Hofmann, Litz, \& Weathers, 2003), GAD (Sigdel et al., 2020), phobias (Cava, Fay, Beanlands, McCay, \& Wignall, 2005) and concerns consequent either to the pandemic, traumatic events that caused the outbreak or social isolation. A final list of 13 items was selected by consensual agreement between researchers or with the aid of a third researcher (S.G.) in case of disagreement.

Each item was scored on 5-point Likert scale $(1=$ "very strongly disagree", $5=$ "very strongly agree").

\section{Results}

\section{Sample characteristics at the first survey}

At baseline (T1), 411 subjects agreed to participate in the survey. Of those, 210 subjects $(51.1 \%)$ also participated in the second administration (T2). At the third administration (T3) 167 subjects replied (40.63\%). Lastly, 147 subjects $(35.76 \%)$ completed the last administration (T4). The sociodemographic characteristics of the sample are presented in Table 1. Responders were mostly female (77\% at baseline, $79 \%$ at $\mathrm{T} 2,82 \%$ at T3, $79 \%$ at T4) and resident in northern Italy $(48.8 \% ; 55.8 \% ; 53.1 \% ; 51.6 \%)$; about a third of participants were students $(27,3 \% ; 34,8 \%$; $35,9 \%, 34,7 \%$ ); the majority live with one family member or are cohabitants (at $\mathrm{T} 1=33,8 \%$; at $\mathrm{T} 2=35,2 \%$; at T3 $=$ $37,7 \%$, at the $\mathrm{T} 4=36,1 \%$ ); about one out of ten had a family member isolated due to COVID-19 (T1=13.6\%, $\mathrm{T} 2=12,9 \%, \mathrm{~T} 3=12 \%$, T4 $=9,5 \%$ ).

At the first survey (baseline, T1), levels of depression measured through PHQ-9 were moderate (10-14) in 14\%, moderately severe (15-19) in $6 \%$ and severe $(+20)$ in $2 \%$ of the responders. Overall, $22 \%$ of the sample exceeded the cut-off score (10), and the PHQ-9 average was found to be significantly higher in the study sample in comparison with normative data $\left(\mathrm{t}_{(411)}=15.03 ; \mathrm{P}=0.000\right.$; Cohen's $d=0.74$ ). Levels of anxiety measured through GAD-7 were moderate in $13 \%$ of the responders and severe in $3 \%$. Overall, about $16 \%$ of participants exceeded the cutoff of 10, and on average our sample showed higher GAD-7 than scores reported for normative samples $\left(\mathrm{t}_{(411)}=13.64 ; \mathrm{P}=0.000 ; d=0.671\right)$. The first set of analyses was conducted in order to test the effect of gender, education, occupation and geographical area categories on PHQ-9 and GAD-7. However, significant differences were found between gender in the levels of GAD-7 $\left(\mathrm{t}_{(148)}=\right.$ 3.29, $\mathrm{P}=0.001, d=0.53)$ and PHQ-9 $\left(\mathrm{t}_{(154)}=2.98, \mathrm{P}=0.001\right.$, $d=0.40$ ) at the baseline, with higher levels of anxiety and 
depression in females. Levels of GAD-7 $\left(\mathrm{F}_{(9,396)}=3.77\right.$, $\left.\mathrm{P}=0.000 ; h^{2}=0.07\right)$ and PHQ-9 $\left(\mathrm{F}_{(9,396)}=4.30, \mathrm{P}=0.000 ; h^{2}\right.$ $=0.09$ ) were also significantly higher at the baseline for the unemployed $(\mathrm{P}=0.010, d=0.61 ; \mathrm{P}=0.015, d=0.56)$ and students $(\mathrm{P}=0.005, d=0.27 ; \mathrm{P}=0.004, d=0.28)$ in comparison with other work categories. There were no significant differences at T1 in GAD-7 and PHQ-9 scores for different levels of education $\left(\mathrm{F}_{(3,402)}=0.616, \mathrm{P}=0.605, d=0.00\right.$; $\left.\mathrm{F}_{(3,402)}=0.837, \mathrm{P}=0.474, d=0.01\right)$, nor in the resident geographical area $\left(\mathrm{F}_{(2,403)}=0.19, \mathrm{P}=0.826, d=0.00 ; \mathrm{F}_{(2,}\right.$, $\left.{ }_{403}=0.353, \mathrm{P}=0.703, d=0.00\right)$. Finally, age proved to be a

Table 1. Sociodemographic characteristics of the sample at the first survey $(\mathrm{N}=411)$.

\begin{tabular}{|c|c|c|}
\hline Sociodemographic characteristics & $\%$ & Mean (SD) \\
\hline Age & & $34,52(12,71)$ \\
\hline \multicolumn{3}{|l|}{ Gender } \\
\hline Male & 23 & \\
\hline Female & 77 & \\
\hline \multicolumn{3}{|l|}{ Geographic area } \\
\hline Northern Italy & 48.8 & \\
\hline Central Italy & 36.7 & \\
\hline Southern Italy & 14.5 & \\
\hline \multicolumn{3}{|l|}{ Occupation } \\
\hline Student & 27.3 & \\
\hline Unemployed & 5.4 & \\
\hline Manual Work & 1.9 & \\
\hline Intellectual Work & 12.2 & \\
\hline Housewife & 2.7 & \\
\hline Retired & 2.7 & \\
\hline Social operator & 3.2 & \\
\hline Healthcare worker & 3.4 & \\
\hline Freelance & 19.5 & \\
\hline Other & 21.9 & \\
\hline \multicolumn{3}{|l|}{ Education } \\
\hline Elementary/Middle school & 5.6 & \\
\hline High school & 29.2 & \\
\hline University & 65.2 & \\
\hline \multicolumn{3}{|l|}{ Household size } \\
\hline One person & 12.4 & \\
\hline Two people & 33.8 & \\
\hline Three people & 27.0 & \\
\hline Four or more people & 23.4 & \\
\hline Other & 3.4 & \\
\hline \multicolumn{3}{|c|}{ Family member isolated due to COVID-19 } \\
\hline Yes & 13.6 & \\
\hline No & 86.4 & \\
\hline
\end{tabular}

factor negatively associated with both GAD-7 $(r=-0.141$; $\mathrm{P}=0.004)$ and PHQ-9 $(r=-0.223 ; \mathrm{P}=0.000)$.

The association of coping strategy (BRCS), social support (MSPSS) and negative emotions (GAD-7 and PHQ9) was also tested at $\mathrm{T} 1$, and showed a significant effect of MSPSS on both anxiety $(\beta=-0.280, \mathrm{P}<0.001)$ and depression $(\beta=-0.318, P<0.001)$ with higher perceived social support associated with less negative emotions, whereas no significant effects were found for coping $(\beta=0.003, \mathrm{P}=0.95$; $\beta=-0.014, P=0.77$, respectively).

\section{Longitudinal changes in anxiety and depression during the different phases of the COVID-19 outbreak}

The following analysis was only conducted on the subsample of participants that had completed at least two out of the three administrations post-baseline. More specifically, 106 subjects completed all four administrations, 31 subjects only the T1, T2 and T3, 20 subjects only the T1, T2 and T4 and, finally, 12 subjects completed only T1, T3 and T4 administrations. Attrition analysis showed that the 169 subjects who continued to participate in the research (with at least 3 data points) did not differ from those who quit after the first survey or had less than 3 time points on GAD ( $\mathrm{t}=-1.92, \mathrm{P}=0.06)$, PHQ $(\mathrm{t}=-1.05$, $\mathrm{P}=0.29)$, MSPSS $(\mathrm{t}=-1.29, \mathrm{P}=0.19)$, whereas the age factor (higher in baseline, $\mathrm{t}=2.56, \mathrm{P}<0.05$ ) and $\mathrm{BRCS}$ (higher in participants who continued, $\mathrm{t}=-4.56, \mathrm{P}<0.01$ ) were significantly different between groups. Distribution of gender, level of education and occupation were similar for the two samples.

$23 \%$ of the 169 participants showed levels of depression above the cut-off at $\mathrm{T} 1$; the percentage remained stable in the two following surveys and then decreased to $16 \%$ at T4. $17 \%$ of participants showed levels of anxiety that exceeded the cut-off; the percentage increased to $23 \%$ at T2 and decreased in the two following surveys (19\% at T3 and 14\% at T4). GAD and PHQ trends were depicted in Figure 1 (see also Supplementary Table A).

Results from the 2-level hierarchical linear model (hlm) showed that PHQ-9 had a significant linear decrease $\left(\beta_{10}=-0.26, \mathrm{P}<0.05\right)$ and a negative quadratic slope $\left(\beta_{20}\right.$ $=-0.51, \mathrm{P}<0.01)$ across time; GAD-7 showed a non-significant linear change but a significant negative quadratic slope $\left(\beta_{20}=-0.28, \mathrm{P}<0.01\right)$. BRCS showed a significant change over time, with a positive quadratic slope $\left(\gamma_{20}=\right.$ $0.13, \mathrm{P}<0.05)$. Finally, social support did not change significantly $\left(\gamma_{20}=0.03, \mathrm{P}>0.05\right)$.

To test the effects of coping and social support on the longitudinal change in anxiety and depression, BRCS and MSPSS were added to the hlm level-1 and level-2 equations. Results showed that coping reduces levels of depression $\left(\beta_{30}=-0.24, \mathrm{P}<0.001\right)$, but not the level of anxiety $\left(\beta_{30}=-0.01, \mathrm{P}=0.87\right)$. Moreover, BRCS did not show significant effects on linear or quadratic slopes for $\operatorname{GAD}\left(\beta_{11}=-0.16, \beta_{21}=-0.02, \mathrm{P}>0.05\right)$ nor for PHQ $\left(\beta_{11}=\right.$ $\left.-0.21, \beta_{21}=-0.02, \mathrm{P}>0.05\right)$. When MSPSS was added to 
the equation, social support negatively predicted both the level of depression $\left(\beta_{30}=-0.91, \mathrm{P}<0.001\right)$ and anxiety $\left(\beta_{30}=-0.57, \mathrm{P}<0.001\right)$. Moreover, MSPSS did not have any significant effect on the linear or quadratic slopes of PHQ $\left(\beta_{11}=-0.12, \beta_{21}=-0.14, \mathrm{P}>0.05\right)$, nor on the slopes for $\operatorname{GAD}\left(\beta_{11}=-0.15, \beta_{21}=-0.03, \mathrm{P}>0.05\right)$ (Table 2).

\section{Transition between outbreak (T1-T2) and post-outbreak (T3-T4)}

Concerns related to the transition between outbreak and post-outbreak were explored with a set of ad-hoc questions. The PCA, used to summarize the answers in fewer principal categories, yielded four factors with eigenvalues exceeding one, accounting for $69 \%$ of the total variance (see Supplementary Table B). None of the 13 items had loadings below 0.40 , while three items showed cross-loadings higher than 0.40 on two factors, thus these 3 items were removed (Table 3 ). Based on the content of the 10 remaining items included in each of the four categories identified, we labeled the first cluster "social withdrawal" because it contained three items that focus on the possible decrease in intention to return to social activities, e.g. "I prefer to continue my activities online even if it is possible to do it in presence"; the second cluster was labeled "fear of contagion" because it collected two affirmations about the increased level of fear in contracting a disease, e.g. "I think that I will have more chance to fall ill"; the third cluster was labeled "worry about wasting free time" because it includes two items referring to the fear of not being able to have enough time to do things during the outbreak, e.g. "I think that I'll go back to not having time for my passions"; finally, the fourth cluster was labeled "fear of confrontation with the outside" because it contained three items regarding the fear of having to reconnect with the social world, e.g. 'I'm worried that I will have to show my physical appearance again". The total score for each category comes from the sum of the scores of related items.

Comparison between T3 and T4 found significant reduction of "social withdrawal" $(\mathrm{F}=11.72 ; \mathrm{P}=0.001$; Cohen's $d=0.039)$ and "fear of contagion" $(\mathrm{F}=4.03$; $\mathrm{P}=0.046$; Cohen's $d=0.014)(\mathrm{T} 3, \mathrm{M}=10.38, \mathrm{SD}=2.91$; $\mathrm{M}=6.01, \mathrm{SD}=2.09$, respectively; $\mathrm{T} 4 \mathrm{M}=9.17, \mathrm{SD}=3.14$; $\mathrm{M}=5.52, \mathrm{SD}=2.05$, respectively), whereas no differences were detected in the other two factors, which were "fear of confrontation with the outside" $(\mathrm{F}=0.27, \mathrm{P}=0.604$, Cohen's $\mathrm{d}=0.001)$ and "worry of waste free time" ( $\mathrm{F}=0.12, \mathrm{P}=0.732$, Cohen's $d=0.001) \quad(\mathrm{T} 3 \mathrm{M}=6.38$, $\mathrm{SD}=2.77 ; \mathrm{M}=5.21 \mathrm{SD}=2.36$, respectively; $\mathrm{T} 4 \mathrm{M}=6.55$ $\mathrm{SD}=2.89 ; \mathrm{M}=5.12 \mathrm{SD}=2.38$, respectively). The GAD-7 was associated with the "fear of confrontation with the outside" at the T3 $(\mathrm{r}=0.379 ; \mathrm{P}=0.000)$ and at $\mathrm{T} 4$ with "social withdrawal" $(\mathrm{r}=0.185 ; \mathrm{p}=.029)$, "fear of contagion" $(\mathrm{r}=0.218 ; \mathrm{P}=0.010)$ and "fear of confrontation with the outside" ( $\mathrm{r}=0.373 ; \mathrm{P}=0.000)$. The PHQ-9 was correlated with "social withdrawal" $(\mathrm{r}=0.209 ; \mathrm{P}=0.010)$, "worry about wasting free time" $(\mathrm{r}=0.159 ; \mathrm{P}=0.053)$ and with "fear of confrontation with the outside" ( $\mathrm{r}=0.380$; $\mathrm{P}=0.000$ ) at the $\mathrm{T} 3$, and with all the four factors ("social withdrawal": $\mathrm{r}=0.254 ; \mathrm{P}=0.003$, "fear of contagion": $\mathrm{r}=0.274 ; \mathrm{P}=0.001$, "worry about wasting free time": $\mathrm{r}=0.164 ; \mathrm{P}=0.054$, and "fear of confrontation with the outside": $\mathrm{r}=0.540 ; \mathrm{P}=0.000$ ) at the $\mathrm{T} 4$.

\section{Discussion}

A growing body of evidence in literature suggests that the COVID-19 pandemic is increasing depression, anxiety

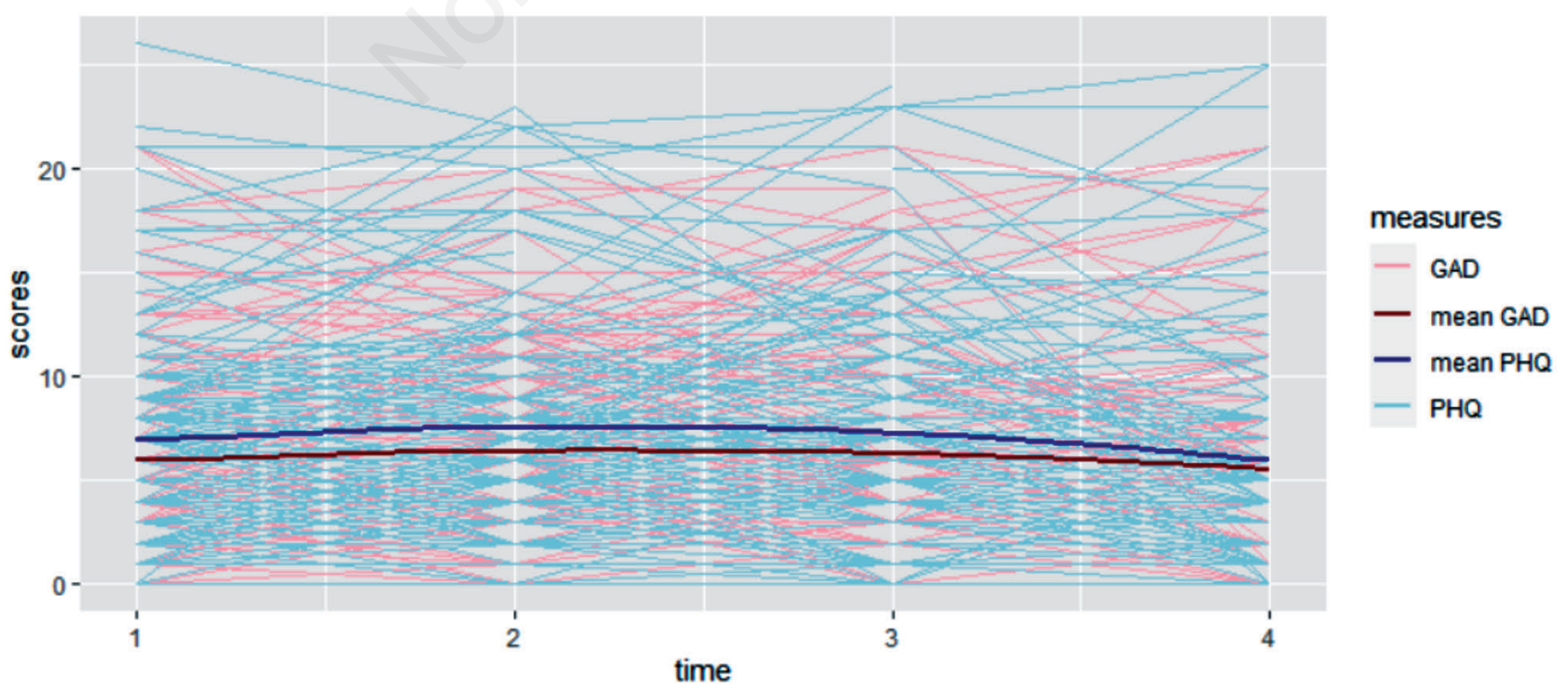

Figure 1. Longitudinal trends for GAD-7 and PHQ-9. 
and other psychological difficulties in the general population and in specific groups (for example, Barzilay et al., 2020; Gualano, Lo Moro, Voglino, Bert, \& Siliquini, 2020; Wang \& Zhao, 2020). In line with results reported by these studies, in our sample of Italian subjects, a high percentage reported clinically relevant levels of anxiety and depression and, on average, these levels remained significantly higher than normative data throughout the three months that we were observing. Interesting findings also emerged from an analysis of the trends of these negative emotions; in fact, the results highlighted the fact that both anxiety and depression had a curvilinear quadratic slope with an increasing at T2 (about three weeks later) and subsequent decreasing at $\mathrm{T} 3$ and $\mathrm{T} 4$ (about five and eight weeks later, respectively). The linear trend, however, showed that, across time, there was a significant decrease in levels of depression but not of anxiety; this is also confirmed by the fact that the levels of anxiety at the last time point (T4) were similar to the initial ones. These results are substantially in line with the findings of Wang et al. (2020b), who reported non-significant change over time in the levels of depression and anxiety, when observations took place at a short time from each other and during the lockdown period.

Apart from common conditions, younger age, female gender, and unemployed or student categories in our sample were found to be more sensitive to negative emotions. The association between age, student condition and anxiety or depression related to the pandemic has already been reported (e.g., Cao et al., 2020; Gualano et al., 2020; Palgi et al., 2020) and it has been suggested that this relationship could be caused by additional stress or generated by the need to have to adapt to the new online educational environment (Ozamiz-Etxebarria et al., 2020). More controversial is COVID-19-related literature regarding gender differences; in fact, despite several studies reporting higher levels of anxiety and depression in females (for example Wang et al., 2020a; Palgi et al., 2020; Rossi et al., 2020), other authors found this association solely with regard to anxiety levels (Gualano et al., 2020); others did not find this association at all (Cao et al., 2020), or found an opposite association, with higher

Table 2. Hierarchical linear model results, fixed effects $(N=169)$.

\begin{tabular}{|c|c|c|c|c|c|}
\hline Fixed effect & Coefficient & SE & $t-$ ratio & Approx. d.f. & P-value \\
\hline \multicolumn{6}{|l|}{$\begin{array}{l}\text { DV: GAD-7 } \\
\quad \text { time slope, } \pi 1\end{array}$} \\
\hline Intercp, $\beta 10$ & -0.512 & 1.877 & -2.994 & 167 & 0.008 \\
\hline BRCS, $\beta 11$ & -0.157 & 0.128 & -1.225 & 167 & 0.222 \\
\hline \multicolumn{6}{|l|}{ time $^{2}$ slope, $\pi 2$} \\
\hline Intercp, $\beta 20$ & -0.656 & 0.720 & -0.911 & 167 & 0.364 \\
\hline BRCS, $\beta 21$ & 0.024 & 0.049 & 0.515 & 167 & 0.607 \\
\hline \multicolumn{6}{|l|}{ BRCS slope, $\pi 3$} \\
\hline Intercp, $\beta 30$ & -0.013 & 0.083 & -0.167 & 168 & 0.868 \\
\hline \multicolumn{6}{|l|}{ time slope, $\pi 1$} \\
\hline Intercp, $\beta 10$ & 1.585 & 1.334 & 1.188 & 167 & 0.236 \\
\hline MSPSS, $\beta 11$ & -0.150 & 0.260 & -0.578 & 167 & 0.564 \\
\hline \multicolumn{6}{|l|}{ time $^{2}$ slope, $\pi 2$} \\
\hline Intercp, $\beta 20$ & -0.152 & 0.448 & -0.341 & 167 & 0.734 \\
\hline MSPSS, $\beta 21$ & -0.030 & 0.089 & -0.339 & 167 & 0.735 \\
\hline \multicolumn{6}{|l|}{ MSPSS slope, $\pi 3$} \\
\hline Intercp, $\beta 30$ & -0.565 & 0.190 & -2.967 & 168 & 0.003 \\
\hline \multicolumn{6}{|l|}{ DV: PHQ-9 } \\
\hline Intercp, $\beta 10$ & -0.256 & 1.859 & 2.225 & 167 & 0.027 \\
\hline BRCS, $\beta 11$ & -0.212 & 0.126 & -1.673 & 167 & 0.096 \\
\hline \multicolumn{6}{|l|}{ time $^{2}$ slope, $\pi 2$} \\
\hline Intercp, $\beta 20$ & -0.743 & 0.789 & -0.942 & 167 & 0.348 \\
\hline BRCS, $\beta 21$ & 0.019 & 0.053 & 0.358 & 167 & 0.721 \\
\hline \multicolumn{6}{|l|}{ BRCS slope, $\pi 3$} \\
\hline Intercp, $\beta 30$ & -0.241 & 0.096 & -2.499 & 168 & 0.013 \\
\hline \multicolumn{6}{|l|}{ time slope, $\pi 1$} \\
\hline Intercp, $\beta 10$ & 0.640 & 1.535 & 0.417 & 167 & 0.677 \\
\hline MSPSS, $\beta 11$ & 0.122 & 0.293 & 0.418 & 167 & 0.677 \\
\hline \multicolumn{6}{|l|}{ time $^{2}$ slope, $\pi 2$} \\
\hline Intercp, $\beta 20$ & 0.182 & 0.527 & 0.346 & 167 & 0.729 \\
\hline MSPSS, $\beta 21$ & -0.138 & 0.100 & -1.373 & 167 & 0.171 \\
\hline \multicolumn{6}{|l|}{ MSPSS slope, $\pi 3$} \\
\hline Intercp, $\beta 30$ & -0.908 & 0.255 & -3.537 & 168 & $<0.001$ \\
\hline
\end{tabular}


anxiety and depression in the male sample (Wang et al., 2020a). Solomou \& Constantinidou (2020) indicated a possible explanation for the negative association with depressive symptoms (repeatedly found in the studies) in the lower compliance with precautionary measures exhibited by men. The relationship between being unemployed and anxiety and depression levels that we found is in line with other studies (Solomou \& Constantinidou, 2020). Unexpectedly, we found no difference in levels of mental health between healthcare workers and non-healthcare workers; although this result was also found by Barzilay et al. (2020), many other studies showed the presence of a relationship between these two domains (Cimerman, Chebabo, Cunha, \& Rodríguez-Morales, 2020; Pappa et al., 2020; Que et al., 2020); we may not have detected this relationship because of the low presence, in our sample, of healthcare workers (3.4\%). Overall, our results suggest that negative emotions related to Coronavirus are persistent and that certain categories of people (young people, women, the unemployed) are particularly vulnerable to this stress.

The present study also investigated the role of protective factors such as coping resources and interpersonal support in reducing people's levels of depression and anxiety over time. It is interesting to note that we found a significant longitudinal increase in coping strategies, while the levels of perceived social support did not change over time. However, we found that interpersonal support facilitates the longitudinal reduction of both depression and anxiety, whereas coping strategies showed a significant protective effect only for depression. Other studies dealing with psychological aspects related to the Coronavirus have gathered similar evidence; a positive effect of social support on anxiety has been found by Cao et al. (2020) and this seems to be confirmed by the findings of Palgi et al. (2020), who identified loneliness as one of the main risk factors for the development of anxious and depressive symptoms during lockdown. Similarly, an association between coping and negative emotions has recently been found in relation to the Coronavirus; for example, Ran et al. (2020) found an inverse association between resilience and anxiety or depression symptoms during the peak of the COVID-19 epidemic in China.

By comparing our longitudinal findings with those found in literature some interesting implications emerge (Maunder et al., 2006). Psychological strategies (e.g. coping and resilience) confirmed their protective effect against a negative mental health condition. However, in the initial phase of the pandemic, people often experienced a sense of helplessness, not feeling ready to confront the pandemic, which reduced the possibility of feeling well psychologically. Although, over time, people

Table 3. Items loadings and label components of ad-hoc items $(\mathrm{N}=169)$.

\begin{tabular}{|c|c|c|c|c|c|}
\hline \multirow[b]{2}{*}{ Items } & \multicolumn{4}{|c|}{ Components } & \multirow[b]{2}{*}{ Component label } \\
\hline & 1 & 2 & 3 & 4 & \\
\hline $\begin{array}{l}\text { 1. I prefer to continue my activities online (study, work, shopping, } \\
\text { gaming etc.) even if it is possible to do it in presence }\end{array}$ & 0.969 & -0.144 & -0.123 & 0.101 & Social withdrawal \\
\hline $\begin{array}{l}\text { 2. I will try to limit attendance in public places (public transport, } \\
\text { bars, restaurants, etc.) more than before the emergency }\end{array}$ & 0.910 & -0.090 & -0.085 & 0.028 & \\
\hline $\begin{array}{l}\text { 7. I think it is safer to continue to carry out only the strictly } \\
\text { necessary activities foreseen in "phase } 1 \text { " }\end{array}$ & 0.574 & 0.261 & 0.193 & -0.245 & \\
\hline 5. I'd rather continue to manage my relationships from home & 0.692 & 0.653 & 0.355 & 0.062 & Removed \\
\hline 4. I feel that I will have more chance to fall ill & 0.481 & 0.395 & 0.073 & -0.115 & Fear of contagion \\
\hline $\begin{array}{l}\text { 3. I am worried that compliance with hygiene rules will not be } \\
\text { enough to guarantee me adequate protection }\end{array}$ & -0.164 & 0.944 & -0.012 & 0.066 & \\
\hline 6. I am worried about having to go back to working in contact with others & 0.658 & 0.728 & 0.425 & 0.330 & Removed \\
\hline 8. I feel that I'll go back to not having time for my passions & 0.001 & 0.845 & -0.080 & 0.043 & $\begin{array}{l}\text { Worry of waste } \\
\text { free time }\end{array}$ \\
\hline $\begin{array}{l}\text { 9. I'm afraid that I won't have, as before the lockdown, enough } \\
\text { time to cultivate my social relationships }\end{array}$ & 0.350 & 0.504 & 0.041 & 0.171 & \\
\hline $\begin{array}{l}\text { 10. I am afraid that the return to normal will coincide with the } \\
\text { return of problems }\end{array}$ & 0.252 & 0.147 & 0.714 & 0.547 & Removed \\
\hline 11. I'm worried that I will have to make my physical appearance again & -0.144 & 0.086 & 0.960 & -0.114 & $\begin{array}{l}\text { Fear of confrontation } \\
\text { with the outside }\end{array}$ \\
\hline 12. I fear that I will no longer be able to indulge in sexual intimacy & 0.010 & -0.068 & 0.912 & 0.049 & \\
\hline $\begin{array}{l}\text { 13. I am terrified of having to face the problems and the crisis } \\
\text { caused by this emergency }\end{array}$ & 0.144 & 0.099 & 0.102 & 0.603 & \\
\hline
\end{tabular}


seem to partially recover greater confidence in their resources and feel more able to adapt to difficulties, it seems that by themselves they cannot achieve a sufficiently high level of resource to be able to neutralize the high levels of anxiety resulting from the pandemic. Therefore, it seems appropriate to point out that psychological support aimed at enhancing people's cognitive resources is an essential goal for psychological intervention in a public health emergency.

This reflection is linked to the need that we felt during our research to understand more deeply the experience that our interviewees were having and which led us to develop a short $a d-h o c$ questionnaire focused on the reactions related to the transition from lockdown to post-lockdown taking place at that time. Therefore, as a third aim of the present study, we explored the kinds of concerns and anxiety that characterized people's return to their normal everyday routine. Data that we collected a few days after the government lifted the lockdown in Italy showed that responses to the items included in the study identified four main areas into which our participants' concerns were organized: social withdrawal, fear of contagion, fear of confrontation with the outside, and worry about wasting free time. These concerns resulted positively significant when associated with the negative emotions explaining the $20 \%$ variance for anxiety and the $30 \%$ for depression, reported by participants.

Interestingly, three weeks after the first administration, "social withdrawal" and "fear of contagion" were reduced significantly, whereas "fear of confrontation with the outside" and "worry about wasting free time" did not significantly decrease. Literature does not provide enough research similar to ours, about the third aim, but some similarity can be found with the attitudes of avoidance and social withdrawal after stressful events such as PTSD (Hofmann et al., 2003). The research that comes closest to our hypothesis concerns what Cava et al. (2005) found after the SARS epidemic, as a result of which, individuals, for fear of being infected, reported a need to remain in quarantine even when government regulations allowed them to go out, or the need to distance themselves from people, to wash themselves often, and wear protective clothing even when the danger was over. In our research, fears decreased in the second part of Phase 2; this could have been the result of less fear on a renewed encounter with the outside world that could have been reassuring for the subjects.

Overall, the results of this study suggest that experiences due to the COVID-19 outbreak have brought on psychological distress to many people, the level of which has remained relatively stable even after the lockdown ended. Anxiety may represent a normal initial response to a significantly stressful event, but when normal life begins to be perceived as more and more remote and difficult, then feelings of depression, loneliness and despair can become more pronounced, especially among the most vul- nerable individuals in society. This challenge to the psychological well-being in society will certainly be launched in increasing proportion to the ability to intervene and handle the symptoms of anxiety among the general public (Gurvich et al., 2020). It is therefore necessary to prepare suitable interventions to tackle the presumed growing psychological malaise and to carry out research that may provide important information for the mental health services (Alves et al., 2020). Interventions regarding the consequences of the COVID-19 outbreak can be interpreted as interventions to tackle the crisis (Dong \& Bouey, 2020; Zgueb et al., 2020). The main objective of the intervention in the crisis is to eliminate the feeling of helplessness and despair present in the patient and to develop a feeling of self-control. The timeliness of taking charge of people's psychological health, focusing in particular on reducing anxiety and depressive phenomena, can help prevent consequences related to various types of long-term psychological disorder that may emerge without such interventions. Further studies should be conducted to confirm, extend, and examine the present results in greater depth. In particular, other longitudinal studies on the progress of difficulties and resources in the long term would be useful. Moreover, the results from our third aim show that post-lockdown re-opening entails rapid changes with certain psychological aspects but not in others; it would be interesting to investigate more thoroughly which aspects improve (and under which conditions) and which others remain problematic. More specifically, our study does not investigate the psychological aspects related to the stigma of having been infected or having had close acquaintances infected. It would be interesting to explore this point, which we believe might have important effects on people's mental health.

Despite the relevance of these data to public health, this study has several limitations. First, the study was conducted on a relatively small sample size, with a high mortality rate between the four time points. Furthermore, a relatively short period of time elapsed between the four administrations. Online self-assessments and non-rigorous random sampling might also have reduced the representativeness and reliability of the results. Besides, the third aim of the study was based on a set of ad-hoc questions, which, therefore, were not standardized and for which there were no normative data, thus making comparison impossible.

\section{Conclusions}

The Coronavirus pandemic and its socio-economic consequences are having a great impact on the psychological well-being of Italians. It is not unreasonable to imagine that this could increase the number of requests for help from the mental health services in the near future. The results of studies such as the present one are strongly recommending the investment of additional resources for 
preventive psychological support for the general public. This could avoid or reduce the aggravation of difficulties, which might subsequently lead to the need for longer and more expensive interventions.

\section{References}

Alves, G. S., Casali, M. E., Veras, A. B., Carrilho, C. G., Bruno Costa, E., Rodrigues, V. M., \& Dourado M. C. N. (2020). A systematic review of home-setting psychoeducation interventions for behavioral changes in dementia: some lessons for the COVID-19 pandemic and post-pandemic assistance. Frontiers in Psychiatry, 11, 577871. doi: 10.3389/fpsyt. 2020.577871

Barzilay, R., Moore, T. M., Greenberg, D. M., DiDomenico, G. E., Brown, L. A., White, L. K., Gur, R. C., \& Gur, R. E. (2020). Resilience, COVID-19-related stress, anxiety and depression during the pandemic in a large population enriched for healthcare providers. Translational Psychiatry, 10(1), 291. doi: https://doi.org/10.1038/s41398-020-00982-4

Brooks, S. K., Webster, R. K., Smith, L. E., Woodland, L., Wessely, S., Greenberg, N., \& Rubin, G. J. (2020). The psychological impact of quarantine and how to reduce it: Rapid review of the evidence. The Lancet, 395(10227), 912-920. https://doi.org/10.1016/S0140-6736(20)30460-8

Cao, W., Fang, Z., Hou, G., Han, M., Xu, X., Dong, J., \& Zheng, J. (2020). The psychological impact of the COVID-19 epidemic on college students in China. Psychiatry Research, 287, 112934. doi: https://doi.org/10.1016/j.psychres.2020. 112934

Cava, M. A., Fay, K. E., Beanlands, H. J., McCay, E. A., \& Wignall, R. (2005). The Experience of Quarantine for Individuals Affected by SARS in Toronto. Public Health Nursing, 22(5), 398-406. doi: https://doi.org/10.1111/j.0737-1209. 2005. 220504.x

Chew, Q., Wei, K., Vasoo, S., Chua, H., \& Sim, K. (2020). Narrative synthesis of psychological and coping responses towards emerging infectious disease outbreaks in the general population: Practical considerations for the COVID-19 pandemic. Singapore Medical Journal, 61(7), 350-356. doi: https://doi.org/10.11622/smedj.2020046

Chiang, H.-H., Chen, M.-B., \& Sue, I.-L. (2007). Self-state of nurses in caring for sars survivors. Nursing Ethics, 14(1), 18-26. doi: https://doi.org/10.1177/0969733007071353

Cimerman, S., Chebabo, A., Cunha, C. A. da, \& RodríguezMorales, A. J. (2020). Deep impact of COVID-19 in the healthcare of Latin America: The case of Brazil. The Brazilian Journal of Infectious Diseases, 24(2), 93-95. doi: https://doi.org/10.1016/j.bjid.2020.04.005

Dong, L., \& Bouey, J. (2020). Public Mental Health Crisis during COVID-19 Pandemic, China. Emerging infectious diseases, 26(7), 1616-1618. doi: https://doi.org/10.3201/eid 2607.200407

El-Zoghby, S. M., Soltan, E. M., \& Salama, H. M. (2020). Impact of the COVID-19 Pandemic on Mental Health and Social Support among Adult Egyptians. Journal of Community Health, 45(4), 689-695. doi: https://doi.org/10.1007/s10900020-00853-5

Fullana, M. A., Hidalgo-Mazzei, D., Vieta, E., \& Radua, J. (2020). Coping behaviors associated with decreased anxiety and depressive symptoms during the COVID-19 pandemic and lockdown. Journal of Affective Disorders, 275, 80-81. doi: https://doi.org/10.1016/j.jad.2020.06.027

Gualano, M. R., Lo Moro, G., Voglino, G., Bert, F., \& Siliquini, R. (2020). Effects of COVID-19 Lockdown on Mental Health and Sleep Disturbances in Italy. International Journal of Environmental Research and Public Health, 17(13), 4779. doi: https://doi.org/10.3390/ijerph17134779

Gurvich, C., Thomas, N., Thomas, E. H., Hudaib, A.-R., Sood, L., Fabiatos, K., Sutton, K., Isaacs, A., Arunogiri, S., Sharp, G., \& Kulkarni, J. (2020). Coping styles and mental health in response to societal changes during the COVID-19 pandemic. International Journal of Social Psychiatry. doi: https://doi.org/10.1177/0020764020961790

Hofmann, S. G., Litz, B. T., \& Weathers, F. W. (2003). Social anxiety, depression, and PTSD in Vietnam veterans. Journal of Anxiety Disorders, 17(5), 573-582. doi: https://doi.org/ 10.1016/S0887-6185(02)00227-X

Hawryluck, L., Gold, W. L., Robinson, S., Pogorski, S., Galea, S., \& Styra, R. (2004). SARS control and psychological effects of quarantine, Toronto, Canada. Emerging Infectious Diseases, 10(7), 1206-1212. doi: https://doi.org/10.3201/ eid1007.030703

Howard, M. C. (2016). A review of exploratory factor analysis decisions and overview of current practices: What we are doing and how can we improve? International Journal of Human-Computer Interaction, 32(1), 51-62. doi: https:// doi.org/10.1080/10447318.2015.1087664

Kroenke, K., Spitzer, R. L., Williams, J. B. W., Monahan, P. O., \& Löwe, B. (2007). Anxiety disorders in primary care: prevalence, impairment, comorbidity, and detection. Annals of Internal Medicine, 146(5), 317. doi: https://doi.org/ 10.7326/0003-4819-146-5-200703060-00004

Kroenke, K., Spitzer, R. L., \& Williams, J. B. W. (2001). The PHQ-9: Validity of a brief depression severity measure. Journal of General Internal Medicine, 16(9), 606-613. doi: https://doi.org/10.1046/j.1525-1497.2001.016009606.x

Kumar, A., \& Nayar, K. R. (2020). COVID 19 and its mental health consequences. Journal of Mental Health, 1-2. doi: https://doi.org/10.1080/09638237.2020.1757052

Liu, C. H., Zhang, E., Wong, G. T. F., Hyun, S., \& Hahm, H. C. (2020). Factors associated with depression, anxiety, and PTSD symptomatology during the COVID-19 pandemic: Clinical implications for U.S. young adult mental health. Psychiatry Research, 290, 113172. doi: https://doi.org/ 10.1016/j.psychres.2020.113172

Löwe, B., Decker, O., Müller, S., Brähler, E., Schellberg, D., Herzog, W., \& Herzberg, P. Y. (2008). Validation and Standardization of the Generalized Anxiety Disorder Screener (GAD-7) in the General Population: Medical Care, 46(3), 266-274. doi: https://doi.org/10.1097/MLR.0b013e318160 d093

Maunder, R., Lancee, W., Balderson, K., Bennett, J., Borgundvaag, B., Evans, S., Fernandes, C., Goldbloom, D., Gupta, M., Hunter, J., McGillis Hall, L., Nagle, L., Pain, C., Peczeniuk, S., Raymond, G., Read, N., Rourke, S., Steinberg, R., Stewart, T., ... Wasylenki, D. (2006). Long-term psychological and occupational effects of providing hospital healthcare during SARS outbreak. Emerging Infectious Diseases, 12(12), 1924-1932. doi: https://doi.org/10.3201/eid1212. 060584

Ozamiz-Etxebarria, N., Dosil-Santamaria, M., Picaza-Gorrochategui, M., \& Idoiaga-Mondragon, N. (2020). Niveles de estrés, ansiedad y depresión en la primera fase del brote 
del COVID-19 en una muestra recogida en el norte de España. Cadernos de Saúde Pública, 36(4), e00054020. doi: https://doi.org/10.1590/0102-311x00054020

Palgi, Y., Shrira, A., Ring, L., Bodner, E., Avidor, S., Bergman, Y., Cohen-Fridel, S., Keisari, S., \& Hoffman, Y. (2020). The loneliness pandemic: Loneliness and other concomitants of depression, anxiety and their comorbidity during the COVID-19 outbreak. Journal of Affective Disorders, 275, 109-111. doi: https://doi.org/10.1016/j.jad.2020. 06.036

Pappa, S., Ntella, V., Giannakas, T., Giannakoulis, V. G., Papoutsi, E., \& Katsaounou, P. (2020). Prevalence of depression, anxiety, and insomnia among healthcare workers during the COVID-19 pandemic: A systematic review and meta-analysis. Brain, Behavior, and Immunity, 88, 901-907. doi: https://doi.org/10.1016/j.bbi.2020.05.026

Qiu, J., Shen, B., Zhao, M., Wang, Z., Xie, B., \& Xu, Y. (2020). A nationwide survey of psychological distress among Chinese people in the COVID-19 epidemic: Implications and policy recommendations. General Psychiatry, 33(2), e100213. doi: https://doi.org/10.1136/gpsych-2020-100213

Que, J., Shi, L., Deng, J., Liu, J., Zhang, L., Wu, S., Gong, Y., Huang, W., Yuan, K., Yan, W., Sun, Y., Ran, M., Bao, Y., \& Lu, L. (2020). Psychological impact of the COVID-19 pandemic on healthcare workers: A cross-sectional study in China. General Psychiatry, 33(3), e100259. doi: https://doi.org/10.1136/gpsych-2020-100259

Ran, L., Wang, W., Ai, M., Kong, Y., Chen, J., \& Kuang, L. (2020). Psychological resilience, depression, anxiety, and somatization symptoms in response to COVID-19: A study of the general population in China at the peak of its epidemic. Social Science \& Medicine, 262, 113261. doi: https://doi.org/10.1016/j.socscimed.2020.113261

Rossi, R., Socci, V., Talevi, D., Mensi, S., Niolu, C., Pacitti, F., Di Marco, A., Rossi, A., Siracusano, A., \& Di Lorenzo, G. (2020). COVID-19 Pandemic and Lockdown Measures Impact on Mental Health Among the General Population in Italy. Frontiers in Psychiatry, 11, 790. https://doi.org/ 10.3389/fpsyt.2020.00790

Serafini, G., Parmigiani, B., Amerio, A., Aguglia, A., Sher, L., \& Amore, M. (2020). The psychological impact of COVID19 on the mental health in the general population. QJM: $A n$ International Journal of Medicine, 113(8), 531-537. doi: https://doi.org/10.1093/qjmed/hcaa201

Sigdel, A., Bista, A., Bhattarai, N., Poon, B. C., Giri, G., Marqusee, H., \& Thapa, subash. (2020). Depression, Anxiety and Depression-anxiety comorbidity amid COVID-19 Pandemic: An online survey conducted during lockdown in Nepal [Preprint]. Public and Global Health. doi: https://doi.org/10.1101/2020.04.30.20086926

Sinclair, V. G., \& Wallston, K. A. (2004). The Development and Psychometric Evaluation of the Brief Resilient Coping Scale. Assessment, 11(1), 94-101. doi: https://doi.org/ $10.1177 / 1073191103258144$

Smith, L., Jacob, L., Yakkundi, A., McDermott, D., Armstrong, N. C., Barnett, Y., ... Tully, M. A. (2020). Correlates of symptoms of anxiety and depression and mental wellbeing associated with COVID-19: A cross-sectional study of UK- based respondents. Psychiatry Research, 291, 113138. doi: https://doi.org/10.1016/j.psychres.2020.113138

Solomou, I., \& Constantinidou, F. (2020). Prevalence and Predictors of Anxiety and Depression Symptoms during the COVID-19 Pandemic and Compliance with Precautionary Measures: Age and Sex Matter. International Journal of Environmental Research and Public Health, 17(14), 4924. doi: https://doi.org/10.3390/ijerph17144924

Spitzer, R. L., Kroenke, K., Williams, J. B. W., \& Löwe, B. (2006). A brief measure for assessing generalized anxiety disorder: the GAD-7. Archives of Internal Medicine, 166(10), 1092. doi: https://doi.org/10.1001/archinte.166. 10.1092

Spitzer, R. L. (1999). Validation and utility of a self-report version of PRIME-MDThe PHQ primary care study. JAMA, 282(18), 1737. doi: https://doi.org/10.1001/jama.282. 18.1737

Vinothkumar, M., Arathi, A., Joseph, M., Nayana, P., Jishma, Ej., \& Sahana, U. (2016). Coping, perceived stress, and job satisfaction among medical interns: The mediating effect of mindfulness. Industrial Psychiatry Journal, 25(2), 195. doi: https://doi.org/10.4103/ipj.ipj_98_14

Wang, C., Pan, R., Wan, X., Tan, Y., Xu, L., Ho, C. S., \& Ho, R. C. (2020a). Immediate psychological responses and associated factors during the initial stage of the 2019 coronavirus disease (COVID-19) Epidemic among the General Population in China. International Journal of Environmental Research and Public Health, 17(5), 1729. doi: https://doi.org/ 10.3390/ijerph17051729

Wang, C., Pan, R., Wan, X., Tan, Y., Xu, L., McIntyre, R. S., Choo, F. N., Tran, B., Ho, R., Sharma, V. K., \& Ho, C. (2020b). A longitudinal study on the mental health of general population during the COVID-19 epidemic in China. Brain, Behavior, and Immunity, 87, 40-48. doi: https://doi.org/ 10.1016/j.bbi.2020.04.028

Wang, J., Wang, J.-X., \& Yang, G.-S. (2020). The psychological Impact of COVID-19 on Chinese Individuals. Yonsei Medical Journal, 61(5), 438. doi: https://doi.org/10.3349 /ymj.2020.61.5.438

Wang, C., \& Zhao, H. (2020). The impact of COVID-19 on anxiety in Chinese University students. Frontiers in Psychology, 11, 1168. doi: https://doi.org/10.3389/fpsyg.2020.01168

Wu, P., Fang, Y., Guan, Z., Fan, B., Kong, J., Yao, Z., Liu, X., Fuller, C. J., Susser, E., Lu, J., \& Hoven, C. W. (2009). The psychological impact of the SARS epidemic on hospital employees in China: exposure, risk perception, and altruistic acceptance of risk. The Canadian Journal of Psychiatry, 54(5), 302-311. doi: https://doi.org/10.1177/070674370905 400504

Zgueb Y, Bourgou S, Neffeti A, Amamou B, Masmoudi J, Chebbi H, Somrani N, Bouasker A. (2020). Psychological crisis intervention response to the COVID 19 pandemic: A Tunisian centralised Protocol. Psychiatry Research, 289, 113042. doi: 10.1016/j.psychres.2020.113042.

Zimet, G. D., Dahlem, N. W., Zimet, S. G., \& Farley, G. K. (1988). The multidimensional scale of perceived social support. Journal of Personality Assessment, 52(1), 30-41. doi: https://doi.org/10.1207/s15327752jpa5201_2 